\title{
Milk consumption and the prepubertal somatotropic axis
} Janet W Rich-Edwards ${ }^{\dagger 1,2,3}$, Davaasambuu Ganmaa ${ }^{\dagger 4}$, Michael N Pollak ${ }^{5}$, Erika K Nakamoto ${ }^{2}$, Ken Kleinman², Uush Tserendolgor ${ }^{6}$, Walter C Willett ${ }^{3,4,7}$ and A Lindsay Frazier*7,8

\begin{abstract}
Address: ${ }^{1}$ Connors Center for Women's Health and Gender Biology, Brigham and Women's Hospital, Boston, USA, ${ }^{2}$ Department of Ambulatory Care and Prevention, Harvard Medical School and Harvard Pilgrim Health Care, Boston, USA, ${ }^{3}$ Department of Epidemiology, Harvard School of Public Health, Boston, USA, ${ }^{4}$ Department of Nutrition, Harvard School of Public Health, Boston, USA, ${ }^{5}$ Division of Cancer Prevention, Department of Oncology, McGill University, Montreal, Canada, ${ }^{6}$ Public Health Institute, Ulaanbaatar, Mongolia, ${ }^{7}$ Channing Laboratory, Brigham and Women's Hospital, Harvard Medical School, Boston, USA and ${ }^{8}$ Department of Pediatric Oncology, Dana-Farber Cancer Institute, Harvard Medical School, Boston, USA

Email: Janet W Rich-Edwards - jrichedwards@partners.org; Davaasambuu Ganmaa - gdavaasa@hsph.harvard.edu; Michael N Pollak - michael.pollak@mcgill.ca; Erika K Nakamoto - Erika_Nakamoto@ harvardpilgrim.org;

Ken Kleinman - ken.kleinman@gmail.com; Uush Tserendolgor - utseren@mongol.net; Walter C Willett - wwillett@hsph.harvard.edu; A Lindsay Frazier* - Lindsay_frazier@dfci.harvard.org

* Corresponding author †Equal contributors
\end{abstract}

Published: 27 September 2007

Nutrition Journal 2007, 6:28 doi:10.1/86/1475-289/-6-28
Received: 19 March 2007

Accepted: 27 September 2007

This article is available from: http://www.nutritionj.com/content/6/1/28

(C) 2007 Rich-Edwards et al; licensee BioMed Central Ltd.

This is an Open Access article distributed under the terms of the Creative Commons Attribution License (http://creativecommons.org/licenses/by/2.0), which permits unrestricted use, distribution, and reproduction in any medium, provided the original work is properly cited.

\begin{abstract}
Background: Nutrients, hormones and growth factors in dairy foods may stimulate growth hormone (GH), insulin-like growth factor I (IGF-I), and raise the ratio of IGF-I to its binding protein, IGFBP-3. We conducted pilot studies in Mongolia and Massachusetts to test the extent to which milk intake raised somatotropic hormone concentrations in prepubertal children.

Methods: In Ulaanbaatar, we compared plasma levels before and after introducing $710 \mathrm{ml}$ daily whole milk for a month among 46 I0-1 I year old schoolchildren. In a randomized cross-over study in Boston, we compared plasma hormone levels of 28 6-8 year old girls after one week of drinking $710 \mathrm{ml}$ lowfat (2\%) milk with their hormone levels after one week of consuming a macronutrient substitute for milk.

Results: After a month of drinking whole milk, Mongolian children had higher mean plasma levels of IGF-I ( $p<0.000$ I), IGF-I/IGFBP-3 ( $p<0.000 \mathrm{I})$, and $75^{\text {th }}$ percentile of GH levels $(p=0.005)$. After a week of drinking lowfat milk, Boston girls had small and non-significant increases in IGF-I, IGF-I/ IGFBP-3 and GH.

Conclusion: Milk drinking may cause increases in somatotropic hormone levels of prepubertal girls and boys. The finding that milk intake may raise $\mathrm{GH}$ levels is novel, and suggests that nutrients or bioactive factors in milk may stimulate endogenous $\mathrm{GH}$ production.
\end{abstract}




\section{Background}

Milk is a complex, bioactive substance honed by evolution to promote growth and development of the infant mammal. Cow's milk and dairy products derived from milk are widely consumed by human children and adults well after the age of weaning. The established health benefits of the macronutrient and micronutrient content of milk include fewer dental caries, increased bone mineral content, fewer fractures, and reduced risk of protein-deficiency malnutrition and rickets [1-6]. However, the impact of other bioactive substances in milk has been little investigated. Dairy products contain bovine hormones and growth factors that may alter the hormone and growth factor levels of prepubertal children.

Several bovine enzymes, hormones, and growth factors are selectively compartmentalized in milk $[7,8]$. Although many hormones and growth factors are destroyed or deactivated during digestion and first-pass hepatic metabolism, several lines of evidence indicate that some hormones or growth factors in milk may survive digestion and remain bioactive in the plasma of milk-drinkers.

Rats fed lowfat (1\%) cow's milk from the Japanese grocer had higher levels of IGF-I and estrone sulfate than animals fed a macronutrient substitute for milk [9]. Several studies of radioactively labeled IGF-I have demonstrated its intact oral absorption and plasma bioactivity in neonate and adult animals, especially when the IGF-I is administered with the protease inhibitor casein, the primary protein in milk [10-15]. Human studies have consistently shown that high milk consumption is associated with a $10 \%-$ $20 \%$ increase in circulating IGF-I levels among adults and a 20\%-30\% increase among children [3,16-22]. Although the proteins in milk could be responsible for the higher IGF-I levels in milk-drinkers, dairy products raise IGF-I levels more than do meat and other sources of dietary protein [17-21]. The ratio of IGF-I to its main binding protein, IGFBP-3, also rises with milk consumption, indicating an increase in bioavailable IGF-I [16-18,20]. Two studies have recently reported that milk intake during pregnancy results in higher birthweight offspring $[23,24]$. The rise in IGF-1 with milk consumption may increase rates of twinning [25].

Most of the steroid hormones and growth factors produced by cows are identical to those produced by humans [26]. If bovine hormones survive the digestive process, most are presumably bioactive. To our knowledge, there has been no macronutrient-controlled experimental investigation of the impact of hormones and growth factors from cow's milk on the plasma hormone and growth factor levels of children. We report here the results of two short-term pilot studies conducted to justify a long-term study of the impact of milk hormones and growth factors on child development.

\section{Methods}

\section{Mongolian Pilot Study}

As children in the US consume large amounts of dairy products, it is difficult to identify a control group with low dairy intake for long-term study. We turned to Mongolia as a possible site for a long-term study. Mongolia has a pastoralist tradition, and milk is a staple of nomadic herders who live on the steppe. Lactose intolerance is virtually unknown. However, a sharp rise in urban migration has resulted in a large group of children whose families lack access to familial herds. Until recently, the only milk available in the capitol city, Ulaanbaatar, was prohibitively expensive imported milk. Ulaanbaatar's children lack access to milk. In Mongolia, we were able to add milk to children's diets, rather than trying to subtract it from the diets of American children. We report here the results of a study conducted to determine the feasibility of a longterm trial of the impact of milk consumption on child development in Ulaanbaatar.

\section{Participants}

With the approval of the Mongolian Ministry of Education and Ministry of Health Ethical Review Board, we conducted a one-month pilot study in Ulaanbaatar from May to June, 2005. The aim of the study was to determine whether participating in research was acceptable to Mongolian parents, children, and institutions, and to test the logistics of shipping milk and blood samples internationally. A letter was sent to the families of all children in a $3^{\text {rd }}$ grade classroom in Public School \#65 in Ulaanbaatar, which included fifty 9-11 year old girls and boys. Families were invited to an informational meeting at the school. The Mongolian investigators (Drs. G and T) explained the study protocol and obtained informed consent from parents and assent from children to participate. Children were eligible if they had no known allergy to milk. One child elected not to enroll, two children responded too late to be enrolled, and one child was withdrawn from the study after developing symptoms of milk allergy. A total of 22 girls and 24 boys completed the protocol.

\section{Procedures}

We performed a physical examination of each child at the beginning and end of the month, with a Tanner Stage evaluation at the first examination only. At baseline, children completed a food frequency questionnaire regarding their consumption of dairy products in the last seven days. During the intervention month, children consumed three 8-ounce tetrapak "boxes" $(710 \mathrm{ml})$ of conventional U.S. UHT-pasteurized vitamin D fortified whole milk daily. The producer of the milk accepts milk only from dairies that do not use bovine somatotropin (BST). From days 4- 
10, four children who experienced digestive upset drank varying amounts of milk $(236,472$, or $710 \mathrm{ml})$ as they grew accustomed to the milk. After day 10, all 46 children drank the full $710 \mathrm{ml}$ daily.

\section{Hormone comparisons}

At the beginning and end of the month, a morning $8 \mathrm{ml}$ blood sample was drawn into a heparinized tube. Blood samples were immediately chilled, and transported cold to a central laboratory, where serum was separated and stored at $-70^{\circ} \mathrm{C}$. Serum levels of growth hormone, IGF-I, and IGFBP-3 were determined in all samples. We compared pre-intervention and post-intervention hormone levels for each child.

\section{Boston Girls and Milk Study Participants}

We conducted a randomized crossover milk feeding study among prepubertal girls, comparing their hormone and growth factor levels after a week of consuming conventional lowfat $(2 \%)$ milk compared with a week of consuming a vegetable-based macronutrient substitute for milk. The study was conducted at the Boston Children's Hospital General Clinical Research Center, and was approved by the Children's Hospital Committee on Clinical Investigation. Thirty-one 6-8 year old girls were recruited from several pediatric clinics and by contacting women who had visited the Cancer Risk and Prevention Clinic of the Dana Farber Cancer Institute. Girls were eligible for the study if their height, weight and body mass index were between the $5^{\text {th }}$ and $95^{\text {th }}$ percentile for age, they had no history of endocrine disorders or clinical signs of pubertal initiation, and they had no allergy to milk or the milk substitute. We obtained consent of parents and assent of the girls for a screening physical and taste-test of the milk substitute. A pediatrician (Dr. F) performed a brief physical to ensure that each girl was in Tanner Stage 1, and the girls tested the palatability of the milk substitute before completing a second consent and assent procedure to enroll in the trial. Three girls did not complete the protocol, due to distaste for the milk substitute, fear of blood draw, or inaccessible veins. We present results for 28 girls who completed the trial. Most girls were Caucasian; 2 were African American, 1 was Native American, and 6 were of Asian descent.

\section{Procedures}

The protocol was five weeks long, including two intervention weeks and an intervening three-week 'wash-out' return to normal diet. In one intervention week, girls consumed $710 \mathrm{ml}$ of $2 \%$ conventional cow's milk per day (from a manufacturer that does not use milk from cows treated with BST). In a second intervention week, the girls drank $710 \mathrm{ml}$ daily of a macronutrient substitute for milk with the same calorie, protein, fat, carbohydrate, calcium and vitamin D content as $2 \%$ cow's milk, concocted from almond milk, coconut milk, and protein powder. During these two intervention weeks, girls consumed otherwise dairy-free diets. The order of the intervention weeks was randomized. At the introductory visit, parents completed a food frequency questionnaire about their daughter's consumption of dairy products over the past year. Girls consumed $99 \%$ of the milk and $92 \%$ of the milk substitute.

\section{Hormone comparisons}

An afternoon $10 \mathrm{ml}$ blood sample was drawn into a heparinized tube at the end of each intervention week, centrifuged, aliquotted, and stored at $-70^{\circ} \mathrm{C}$. We compared the hormone and growth factor level of each girl at the end of the milk week to her level at the end of the milk substitute week.

\section{Hormone and growth factor analysis for both studies}

GH, IGF-I, and IGFBP-3 were assayed by enzyme-linked immunoabsorbent assay (ELISA) with reagents from Diagnostic Systems Laboratory (Webster, Texas). The IGFI values obtained by ELISA in our laboratory are highly correlated (Pearson $r=0.97$ ) with values obtained by radioimmunoassay after acid chromatography. The average intra-assay coefficients of variation for IGF-I, IGFBP-3, and GH were $4.9 \%, 9.0 \%$, and $8.0 \%$, respectively. The IGF-I assay was run in two batches, with limits of detection of $14 \mathrm{ng} / \mathrm{ml}$ and $21 \mathrm{ng} / \mathrm{ml}$, respectively (both samples for each child were included in the same batch). The limits of detection were $2 \mathrm{ng} / \mathrm{ml}$ for the IGFBP-3 assay and 0.2 $\mathrm{ng} / \mathrm{ml}$ for the GH assay. Results below the limit of detection were assigned the limit of detection for analysis.

\section{Statistical analysis for both studies}

We performed paired t-tests of differences in the means of IGF-I and the IGF-I/IGFBP3 ratio; the GH distribution was too skewed to apply a parametric test. We used unpaired quantile regression to test differences in the $50^{\text {th }}$ and $75^{\text {th }}$ percentiles of the distributions. We report the $75^{\text {th }}$ percentile because more than half the GH values were at or below the limit of detection, and the $75^{\text {th }}$ percentile captured variation above this "floor" limit. Paired statistical techniques for quantile regression are not available; however, unpaired analyses are valid but would be less powerful than paired techniques if they existed. To display results graphically, we estimated kernel density distributions of hormone and growth factor levels [27]. All analyses were performed using SAS (version 9.1) software.

\section{Results}

Characteristics of children in the two pilot studies are presented in Table 1. Mongolian children are somewhat smaller and leaner than their U.S. peers, with a profile similar to that of U.S. 9-10 year olds [28]. The height, 
Table I: Mean (sd) baseline characteristics of participants in two pilot studies

\begin{tabular}{lccc}
\hline & Mongolian boys & Mongolian girls & Boston girls \\
\hline $\mathrm{n}$ & 24 & 22 & 28 \\
Age & $10.4(0.7)$ & $10.6(0.6)$ & $7.6(0.9)$ \\
Weight $(\mathrm{kg})$ & $29.1(0.7)$ & $28.8(1.0)$ & $25.6(4.6)$ \\
Height $(\mathrm{cm})$ & $132.5(1.4)$ & $130.8(1.3)$ & $123.9(6.6)$ \\
BMI $\left(\mathrm{kg} / \mathrm{m}^{2}\right)$ & $16.5(0.3)$ & $16.8(0.3)$ & $16.6(2.0)$ \\
Tanner stage $>1$ & $12 \%(3 / 24)$ & $4 \%(1 / 22)$ & $0 \%(\mathrm{by} \mathrm{design)}$ \\
Per week: & & $0.5(1.0)$ & $14.9(5.8)$ \\
Servings of milk & $0.8(1.3)$ & $4.1(4.0)$ & $18.9(10.3)$ \\
Servings of other dairy' & $6.5(6.0)$ & & \\
\hline
\end{tabular}

I. "Other dairy" for the Boston girls included cheese, ice cream, yoghurt, and cheese-containing dishes such as pizza or pasta. "Other dairy" for the Mongolia children consisted of cheese, yoghurt, or milk added to tea.

weight and body mass index (BMI, $\mathrm{kg} / \mathrm{m}^{2}$ ) of the Boston girls was typical for U.S. girls age 6-8 years [28]. The Mongolian children consumed an average 0.6 servings of whole milk, 0.7 servings of cheese/week, and 1.6 servings of yoghurt in the week before the intervention. Fifteen percent of children had no dairy intake at all, confirming anecdotal reports of low dairy intake among Mongolian urban children. The Boston girls typically consumed 15 glasses of predominantly lowfat or skim milk per week, with an average 19 servings of other dairy products per week.

Figure 1 shows the kernel density estimated distributions of GH, IGF-I, and IGF-I/IFGBP-3 according to milk intervention arm in each study. As expected, the distribution of GH in both studies was skewed, with the median values in both studies at or near the limit of detection. The highest GH values were observed after milk consumption in both studies. In Mongolia, large increases in IGF-I and IGF-I/ IGFBP-3 levels were observed between the beginning and end of the milk intervention month. In Boston, there was a subtle shift of the IGF-I and IGF-I/IGFBP-3 distributions to higher levels after a week of consuming milk, compared with a week of consuming milk substitute.

During the milk intervention month in Mongolia, girls grew a mean $1.1(0.2 \mathrm{sd})$ centimeters, $0.65(0.2) \mathrm{kg}$, and had a mean drop in BMI of $-0.29(0.06)$. Boys grew a mean $1.0(0.2)$ centimeters, $0.23(0.1) \mathrm{kg}$, and had a mean decrease in BMI of $-0.26(0.06)$. Consistent with the rapid increase in height over the intervention month, we observed large increases in serum GH, IGF-I, and IGF-I/ IGFBP-3 (Table 2). Large differences in the means, medians, and $75^{\text {th }}$ percentile of these somatotropic hormones were statistically significant, with the exception of median $\mathrm{GH}$, which was nearly doubled but was not statistically significant. Changes in GH and growth factor levels from the beginning to the end of the milk intervention month were similar for girls and boys (data not shown).
Table 3 shows the results of statistical tests of the plasma assays in the Boston trial. The mean, median, and 75th percentiles were higher during the week in which the girls drank milk, but these differences were neither large nor statistically significant in these 6-8 year olds.

\section{Discussion}

In a Mongolian pilot study, levels of prepubertal GH, IGFI, and IGF-I/IGFBP-3 were markedly higher after one month of drinking milk. In the smaller, shorter Boston pilot study, which contrasted cow's milk to a macronutrient control for cow's milk, levels of GH, IGF-I and IGF-I/ IGFBP3 were not elevated, although we observed a small non-significant shift in somatotropin levels in the direction of the Mongolian findings. The rise in somatotropic hormone and growth factor levels was larger in the Mongolian than in the Boston study, perhaps due to the longer intervention, the fact that the Mongolian children consumed less dairy at baseline, the use of whole versus lowfat milk, the older age of the Mongolian participants, or the baseline nutritional status of the Mongolian children.

We conducted the Mongolian feasibility pilot with limited resources, and therefore did not attempt a macronutrient control. During the intervention month, the Mongolian children experienced rapid linear growth (the equivalent of $12 \mathrm{~cm}$ /year) compared to an average height velocity of 5-6 cm/year in U.S. children age 10-11 years [29]. Although such rapid growth suggests that the children may have been undernourished at the start of the trial, the increase in GH is unlikely to be a refeeding effect of milk nutrients. The classic hormonal profile in undernutrition is low IGF-I, but stable or even elevated GH levels [30-33]. High GH during fasting may promote the tissue-sparing switch from gluconeogenesis to lipolysis during periods of undernutrition [30,31]. On refeeding, IGF-I levels increase, but GH levels typically fall [31,32]. In the Mongolian children, the increase in GH levels after milk consumption was proportionally higher than the increase in 
A) Mongolian Growth Hormone

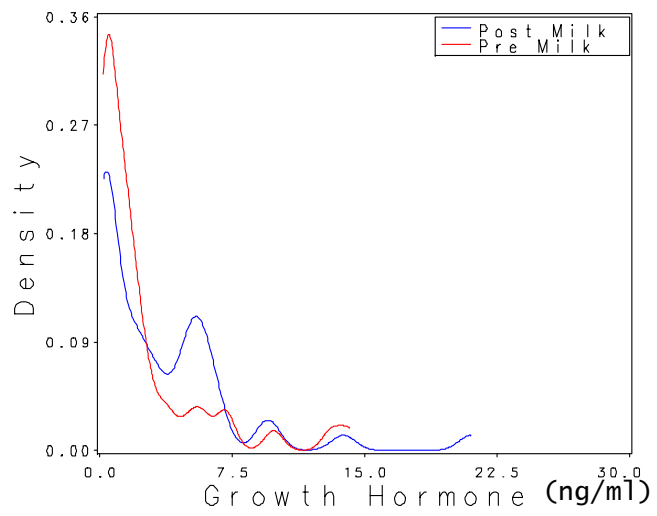

C) Mongolian IGF-I

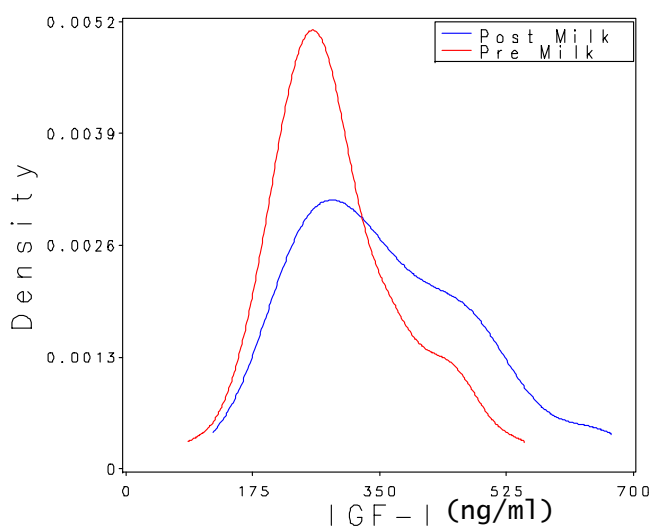

E) Mongolian IGF-I/IGFBP-3

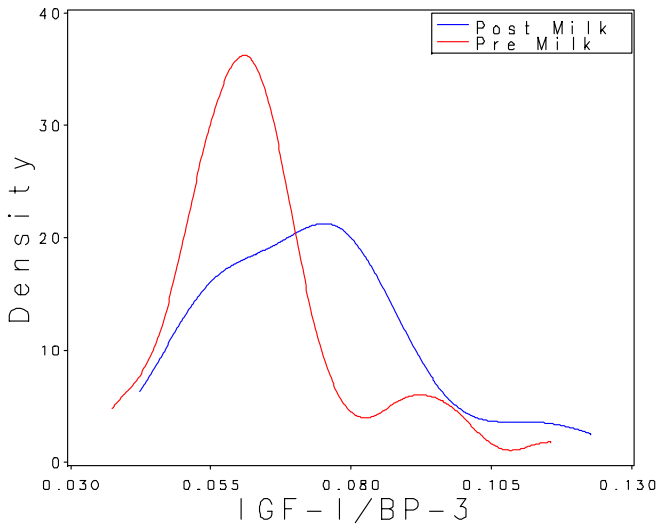

B) Boston Growth Hormone

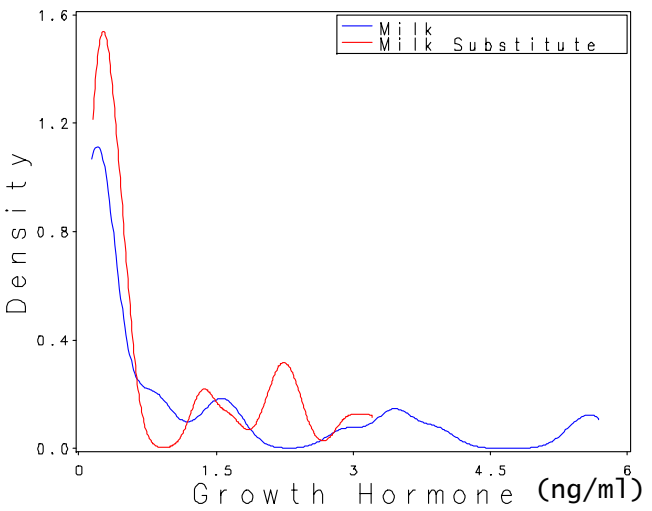

D) Boston IGF-I

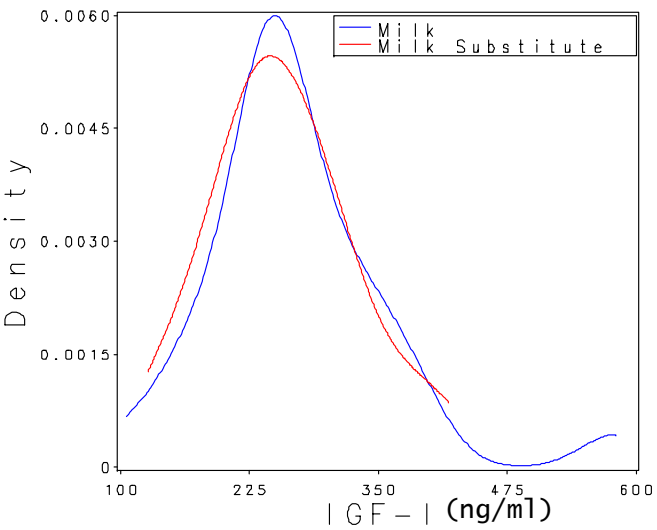

F) Boston IGF-I/IGFBP-3

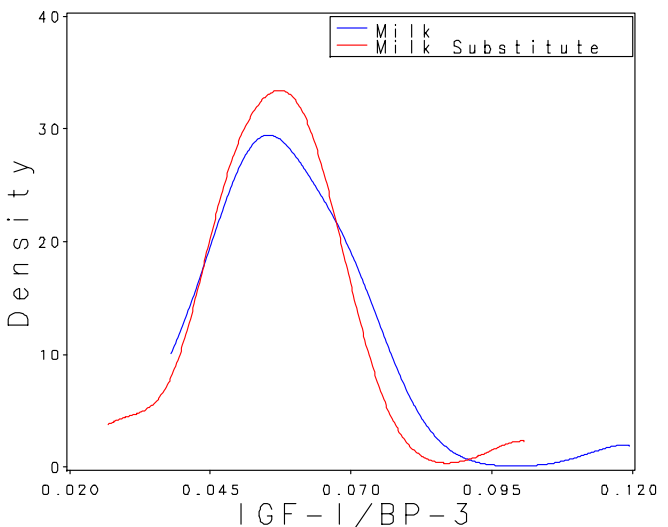

\section{Figure I}

Distributions of plasma somatotropic hormones in two pilot studies. The Mongolia study compared concentrations of growth hormone (GH) (Ia), insulin-like growth factor I (IGF-I) (Ib), and the ratio of IGF-I to its binding protein 3 (IGF-I/ IGFBP-3) (Ic) among 9-II year old Mongolian boys and girls $(n=46)$ before (red line) and after (blue line) one month of drinking $710 \mathrm{ml}$ whole milk daily. The Boston study included 6-8 year old girls $(n=28)$ whose concentrations of GH (Id), IGF-I (Ie), and the ratio of IGF-I/IGFBP-3 (If) were measured after I week consuming $710 \mathrm{ml}$ of lowfat milk daily (blue line) and one week of consuming a vegetable-based macronutrient substitute for milk (red line). a) Mongolian GH. b) Boston GH. c) Mongolian IGF-I. d) Boston IGF-I. e) Mongolian IGF-I/IGFBP-3. f) Boston IGF-I/IGFBP-3. 
Table 2: Change in 10 year-old Mongolian children's hormone and growth factor concentrations before and after one month of drinking $710 \mathrm{ml}$ of American UHT whole milk daily.

\begin{tabular}{llccc}
\hline Mongolia & & Mean & 50th percentile & $\mathbf{7 5}^{\text {th }}$ percentile \\
\hline Growth Hormone $(\mathbf{n g} / \mathbf{m l})$ & Pre & $2.38 \pm 3.27$ & 1.23 & 2.60 \\
& Post & $3.42 \pm 4.07$ & 2.14 & 5.28 \\
& P-value & NA* & 0.23 & 0.005 \\
\hline IGF-I (ng/mI) & Pre & $290.93 \pm 93.98$ & 270.70 & 346.95 \\
& Post & $358.34 \pm 125.62$ & 333.56 & 449.29 \\
& P-value & $<0.0001$ & 0.04 & 0.03 \\
\hline \multirow{2}{*}{ IGF-I/IGFBP-3 } & Pre & $0.064 \pm 0.016$ & 0.062 & 0.068 \\
& Post & $0.073 \pm 0.019$ & 0.072 & 0.082 \\
& P-value & $<0.0001$ & 0.009 & 0.007 \\
\hline
\end{tabular}

For means, $\mathrm{p}$-values are from paired t-tests. For $50^{\text {th }}$ and $75^{\text {th }}$ percentiles, $\mathrm{p}$-values are from unpaired quantile regression.

* T-test comparing mean GH not appropriate, due to non-Normal GH distribution.

either IGF-I or IGF-I/IGFBP-3 levels. This finding is inconsistent with a malnutrition correction effect. As GH is released in a pulsatile fashion, and we had only one GH measurement in these pilot studies, we undoubtedly overestimated the variability of $\mathrm{GH}$, reducing our statistical power to detect a GH response to milk. Future studies should measure GH more frequently to capture GH secretory dynamics and better estimate GH levels.

Our studies suggest an immediate stimulatory impact of milk on the secretion of GH and bioactive IGF-I. Other studies suggest that the impact of milk on IGF-I levels is maintained, and may grow over time. In China, 10 year old girls randomized to consume whole milk had $9 \%$ higher IGF-I levels after one year, and 20\% higher levels after two years $(\mathrm{p}<0.05)$ [2]. In Britain, 12 year-old girls randomized to drink approximately $300 \mathrm{ml} /$ day of milk had 10\% higher IGF-I levels after 6 months of intervention, and $17 \%$ higher levels at months 12 and 18 of inter- vention ( $p=0.02)$ [3]. To our knowledge, ours is the first study to report GH response to dairy intake, which was large and statistically significant among the Mongolian children.

The findings here should be replicated in larger studies with macronutrient and micronutrient control. If consistent findings emerge, it would be important to identify the specific bioactive factor in bovine milk that raises GH and IGF-I levels. Although human and bovine GH are not identical, bovine GH absorbed from milk might crossreact with the human GH assay, and it is conceivable (but as yet untested) that bovine GH might stimulate human IGF-I production. Animal feeding experiments, using radioactively labeled bovine vs. human $\mathrm{GH}$, would be an approach to answering the question of the origin of elevated GH we observed in the children's serum. Alternatively, another factor in bovine milk may stimulate endogenous production of human GH, which would, in

Table 3: Comparison of hormone and growth factor levels among 6-8 year old Boston girls after I week milk consumption versus I week macronutrient substitute for milk $(n=28)$.

\begin{tabular}{|c|c|c|c|c|}
\hline Boston & & Mean & $50^{\text {th }}$ percentile & $75^{\text {th }}$ percentile \\
\hline \multirow[t]{3}{*}{ Growth Hormone (ng/ml) } & After substitute & $0.89 \pm 0.96$ & 0.41 & 1.52 \\
\hline & After milk & $1.25 \pm 1.67$ & 0.21 & 1.62 \\
\hline & $\mathrm{P}$-value & NA* & 0.63 & 0.93 \\
\hline \multirow[t]{3}{*}{ IGF-I (ng/ml) } & After substitute & $257.26 \pm 69.12$ & 250.36 & 294.71 \\
\hline & After milk & $270.60 \pm 89.46$ & 250.20 & 308.77 \\
\hline & p-value & 0.35 & 0.99 & 0.68 \\
\hline \multirow[t]{3}{*}{ |GF-I/IGFBP-3 } & After substitute & $0.057 \pm 0.01$ & 0.057 & 0.064 \\
\hline & After milk & $0.059 \pm 0.02$ & 0.056 & 0.068 \\
\hline & $\mathrm{p}$-value & 0.28 & 0.72 & 0.28 \\
\hline
\end{tabular}

For means, $\mathrm{p}$-values are from paired $\mathrm{t}$-tests. For $50^{\text {th }}$ and $75^{\text {th }}$ percentiles, $\mathrm{p}$-values are from unpaired quantile regression.

*T-test comparing mean $\mathrm{GH}$ is not appropriate, due to non-Normal GH distribution 
turn, provoke IGF-I production. Although bovine and human IGF-I are identical, IGF-I absorbed from milk is unlikely to stimulate human GH secretion, as GH levels should drop in response to negative feedback from IGF-I infusion. Future analysis should focus on identifying factors in milk that could stimulate human GH secretion, such as growth hormone releasing hormone, ghrelin, or a substance that stimulates ghrelin release.

\section{Conclusion}

Milk drinking may cause increases in somatotropic hormone levels of prepubertal girls and boys. The finding that milk intake may raise GH levels is novel, and suggests that nutrients or bioactive factors in milk may stimulate endogenous GH production.

$$
\begin{aligned}
& \text { Abbreviations } \\
& \text { BMI = body mass index }\left(\mathrm{kg} / \mathrm{m}^{2}\right) \\
& \text { BST = bovine somatotropin } \\
& \text { GH = growth hormone } \\
& \text { IGF-I = insulin-like growth factor I }
\end{aligned}
$$$$
\text { IGFBP-3 = insulin-like growth factor binding protein } 3
$$

\section{Competing interests}

The author(s) declare that they have no competing interests.

\section{Authors' contributions}

JRE, DG, LF, WW, and EN designed the study. DG and UT conducted the Mongolian pilot study. LF, JRE, and EN conducted the Boston study. MP contributed hormone assays and interpretation. KK and EN performed statistical analyses. JRE drafted the manuscript, and all contributors have edited and approved the manuscript.

\section{Acknowledgements}

These projects were funded by the Breast Cancer Research Foundation; grant MOI-RR02172 from the National Center for Research Resources, National Institutes of Health to the Children's Hospital Boston General Clinical Research Center; a translational acceleration grant to Dr. Pollak from the Canadian Breast Cancer Research Alliance; and charitable contributions by the Boston office of Deloitte \& Touche LLP and the Ames Family Foundation.

We are grateful to the participants in the Boston Girls and Milk Study, the families and staff of Ulaanbaatar Public School \#65, Mongolian Ministry of Health, Mongolian Ministry of Education, Mongolian Public Health Institute, Dr. Surdaa, Dr. Jambalmaa, Dr. David Fraser, Mr. Gary Bradwin and Ms. Nyan Chu, Staff of the Boston Children's Hospital General Clinical Research Center, Dr. Henry Feldman of the Clinical Research Program at Boston Children's Hospital, Dr. Judy Garber and staff of the Dana Farber Cancer Risk and Prevention Clinic, and the staff and pediatricians at Long- wood Pediatrics and the Children's Hospital Primary Care Clinic who referred patients to our study.

\section{References}

I. Du X, Zhu K, Trube A, Zhang Q, Ma G, Hu X, Fraser DR, Greenfield $\mathrm{H}$ : School-milk intervention trial enhances growth and bone mineral accretion in Chinese girls aged $10-12$ years in Beijing. British Journal of Nutrition 2004, 9 I: I-I I.

2. Zhu K, Du X, Cowell CT, Greenfield H, Blades B, Dobbins TA, Zhang $Q$, Fraser DR: Effects of school milk intervention on cortical bone accretion and indicators relevant to bone metabolism in Chinese girls aged I0-12 y in Beijing. Am J Clin Nutr 2005, 81: I 168-1175.

3. Cadogan J, Eastell R, Jones N, Barker ME: Milk intake and bone mineral acquisition in adolescent girls: randomised, controlled intervention trial. $B M]$ | 997 , 3 | 5: | $255-1260$.

4. Kalkwarf HJ, Khoury JC, Lanphear BP: Milk intake during childhood and adolescence, adult bone density, and osteoporotic fractures in US women. Am J Clin Nutr 2003, 77:257-265.

5. Nicklas TA: Calcium intake trends and health consequences from childhood through adulthood. J Am Coll Nutr 2003, 22:340-356.

6. Elwood PC, Pickering JE, Hughes J, Fehily AM, Ness AR: Milk drinking, ischaemic heart disease and ischaemic stroke II. Evidence from cohort studies. Eur J Clin Nutr 2004, 58:7I 8-724.

7. Grosvenor CE, Picciano MF, Baumrucker CR: Hormones and growth factors in milk. Endocr Rev 1993, 14:710-728.

8. Rodriguez-Palmero M, Koletzko B, Kunz C, Jensen R: Nutritional and biochemical properties of human milk: II. Lipids, micronutrients, and bioactive factors. Clin Perinatol 1999, 26:335-359.

9. Qin LQ, Xu JY, Wang PY, Ganmaa D, Li J, Wang J, Kaneko T, Hoshi $K$, Shirai T, Sato A: Low-fat milk promotes the development of 7,12-dimethylbenz(A)anthracene (DMBA)-induced mammary tumors in rats. Int J Cancer 2004, I I 0:491-496.

10. Kimura T, Murakawa Y, Ohno M, Ohtani S, Higaki K: Gastrointestinal Absorption of Recombinant Human Insulin-Like Growth Factor-I in Rats. Journal of Pharmacology and Experimental Therapeutics 1997, 283:6||-6|8.

II. Philipps AF, Kling PJ, Grille JG, Dvorak B: Intestinal transport of insulin-like growth factor-I (igf-I) in the suckling rat. J Pediatr Gastroenterol Nutr 2002, 35:539-544.

12. Pacha J: Development of intestinal transport function in mammals. Physiol Rev 2000, 80:1633-1667.

13. Rao RK, Lam K, Philipps AF, Williams C, Lake M, Koldovsky O: Presence of multiple forms of peptidase inhibitors in rat milk. J Pediatr Gastroenterol Nutr 1993, 1 7:4|4-420.

14. Vacher PY, Bestetti G, Blum JW: Insulin-like growth factor I absorption in the jejunum of neonatal calves. Biol Neonate 1995, 68:354-367.

15. Xu RJ, Wang T: Gastrointestinal absorption of insulin-like growth factor-I in neonatal pigs. J Pediatr Gastroenterol Nutr 1996, 23:430-437.

16. Ma J, Giovannucci E, Pollak M, Chan JM, Gaziano JM, Willett W, Stampfer MJ: Milk intake, circulating levels of insulin-like growth factor-I, and risk of colorectal cancer in men. J Natl Cancer Inst 200I, 93: I330-I 336.

17. Giovannucci E, Pollak M, Liu Y, Platz EA, Majeed N, Rimm EB, Willett WC: Nutritional predictors of insulin-like growth factor I and their relationships to cancer in men. Cancer Epidemiol Biomarkers Prev 2003, I 2:84-89.

18. Holmes MD, Pollak MN, Willett WC, Hankinson SE: Dietary correlates of plasma insulin-like growth factor $I$ and insulin-like growth factor binding protein 3 concentrations. Cancer Epidemiol Biomarkers Prev 2002, I I:852-86I.

19. Hoppe C, Udam TR, Lauritzen L, Molgaard C, Juul A, Michaelsen KF: Animal protein intake, serum insulin-like growth factor $I$, and growth in healthy 2.5-y-old Danish children. Am J Clin Nutr 2004, 80:447-452.

20. Hoppe C, Mølgaard C, Juul A, Michaelsen KF: High intakes of skimmed milk, but not meat, increase serum IGF-I and IGFBP-3 in eight-year-old boys. European Journal of Clinical Nutrition 2004, 58:121।-1216.

21. Rogers IS, Gunnell D, Emmett PM, Glynn LR, Dunger DB, Holly JM: Cross-sectional associations of diet and insulin-like growth 
factor levels in 7- to 8-year-old children. Cancer Epidemiol Biomarkers Prev 2005, 14:204-2I 2 .

22. Heaney RP, McCarron DA, Dawson-Hughes B, Oparil S, Berga SL, Stern JS, Barr SI, Rosen CJ: Dietary changes favorably affect bone remodeling in older adults. J Am Diet Assoc 1999, 99:1228-1233.

23. Mannion CA, Gray-Donald K, Koski KG: Association of low intake of milk and vitamin $D$ during pregnancy with decreased birth weight. Canadian Medical Association Journal 2006, 174:1273-1277.

24. Olsen SF, Halldorsson Th I, Willett WC, Knudsen VK, Mikkelsen TB, Gillman MW, Olsen J, Consortium N: Association of milk consumption in pregnancy with increased foetal growth. Pediatric Research 2005, 58: I I 20-II 20.

25. Steinman G: Mechanisms of twinning. VII. Effect of diet and heredity on the human twinning rate. J Reprod Med 2006, $5 \mathrm{I}: 405-410$

26. Goffin V, Shiverick KT, Kelly PA, Martial JA: Sequence-function relationships within the expanding family of prolactin, growth hormone, placental lactogen, and related proteins in mammals. Endocr Rev 1996, 17:385-410.

27. Scott DW: Multivariate Density Estimation: Theory, Practice, and Visualization New York: John Wiley \& Sons, Inc; 1992.

28. CDC Growth Charts: United States [http://www.cdc.gov/nchs/ about/major/nhanes/growthcharts/datafiles.htm]

29. Tanner JM: Foetus into Man. Physical Growth from Conception to Maturity Cambridge, MA: Harvard University Press; 1990.

30. Ho K, Veldhuis JD, Johnson M, Furlanetto R, Evans WS, Alberti KG, Thorner MO: Fasting enchances growth hormone secretion in man. J Clin Invest 1988, 81:968-975.

31. Soliman AT, EIZalabany MM, Salama M, Ansari BM: Serum leptin concentrations during severe protein-energy malnutrition: correlation with growth parameters and endocrine function. Metabolism 2000, 49:819-825.

32. Soliman AT, Hassan AE, Aref MK, Hintz RL, Rosenfeld RG, Rogol AD: Serum insulin-like growth factors $I$ and II concentrations and growth hormone and insulin responses to arginine infusion in children with protein-energy malnutrition before and after nutritional rehabilitation. Pediatr Res 1986, 20: I I22-I I30.

33. Hintz RL, Suskind R, Amatayakul K, Thanangkul O, Olson R: Plasma somatomedin and growth hormone values in children with protein-calorie malnutrition. J Pediatr 1978, 92:153-156.

\section{Publish with Bio Med Central and every scientist can read your work free of charge}

"BioMed Central will be the most significant development for disseminating the results of biomedical research in our lifetime. "

Sir Paul Nurse, Cancer Research UK

Your research papers will be:

- available free of charge to the entire biomedical community

- peer reviewed and published immediately upon acceptance

- cited in PubMed and archived on PubMed Central

- yours - you keep the copyright
BioMedcentral 